\title{
Patient Satisfaction with a Tertiary Hospital in Egypt using a HCAHPS-Derived Survey
}

\author{
Mahmoud Farghaly' \\ Abdallah Kamal ${ }^{1,2}$ \\ Maged El-Setouhy (iD ${ }^{3,4}$ \\ Jon Mark Hirshon (iD) 5,6 \\ Mohamed El-Shinawi (iD) ${ }^{1,7}$ \\ 'Department of General Surgery, Ain \\ Shams University, Cairo, Egypt; \\ ${ }^{2}$ Department of Radiology, Hillman \\ Cancer Center, University of Pittsburgh, \\ Pittsburgh, PA, USA; ${ }^{3}$ Department of \\ Community, Environmental and \\ Occupational Medicine, Ain Shams \\ University, Cairo, Egypt; ${ }^{4}$ Department of \\ Family and Community Medicine, Jazan \\ University, Jazan, Saudi Arabia; \\ ${ }^{5}$ Department of Emergency Medicine, \\ University of Maryland School of \\ Medicine, Baltimore, MD, USA; \\ ${ }^{6}$ Department of Epidemiology and Public \\ Health, University of Maryland School of \\ Medicine, Baltimore, MD, USA; \\ ${ }^{7}$ Department of Medical Education, \\ Galala University, Cairo, Egypt
}

Correspondence: Mahmoud Farghaly Department of General Surgery, Ain Shams University, Cairo, Egypt

$\mathrm{Tel}+201001775378$

Email Mahmoudfarghali@med.asu.edu.eg
Study Design: Retrograde cross-sectional study.

Objective: To assess patient satisfaction and outcomes in polytraumatized patients in ELDemerdash hospital.

Background: This is the first study that assessed patient satisfaction with a tertiary hospital in Egypt. Ain Shams University Surgery Hospital, which is one of the largest hospitals in Egypt and serves millions of patients each year, was the site of the study.

Methods: A version of the Hospital Consumer Assessment of Healthcare Providers and Systems (HCAHPS) survey was used to query 361 patients from November 2015 until July 2018 Survey questions were divided into the following categories: communication with doctors, responsiveness of hospital staff, cleanliness of the hospital environment, quietness of the hospital environment, pain management, communication about medicines, discharge information, overall rating of the hospital, and willingness to recommend the hospital.

Results: A total of 361 patients were interviewed. The results showed both positive and negative levels of satisfaction. The positive results included no delay in admission, friendly staff including nurses and doctors, better patient outcomes regarding pain management and adverse side effects, and the overall rating of the hospital was good, which reflected patient satisfaction. The negative findings were lack of proper communication between the medical staff and patients. Patients indicated they did not get a satisfactory explanation of their prescribed drug doses and drug adverse effects. In addition, they did not get enough instruction on what to do after being released from the hospital.

Conclusion: The medical staff at Ain Shams University Surgery Hospital should focus more on the patient's own preferences and communicate better with patients. We recommended that the hospital organize regular communication skills courses for medical students, physicians, and nurses. Patients should understand the discharge report and indications and side effects of the medications before leaving the hospital.

Keywords: HCAHPS, quality, patients' satisfaction, community

\section{Introduction}

Patient satisfaction is the concept of subjective personal perception of received health services, and its measurement and improvement are essential for maintaining a successful high-quality health care system $^{1,2}$. Patient satisfaction is mainly achieved by a patient-centered approach that focuses on a proper understanding and involvement of the patient in the provided care ${ }^{3}$. Continuous monitoring of patient satisfaction and attitudes toward provided services is crucial for maintaining a successful and efficient high-quality health care system ${ }^{2}$. Moreover, research has suggested that higher patient satisfaction was associated with significantly better 
outcomes, decreased mortality rates, shorter hospital stays, and lower readmission rates ${ }^{4,5}$. A possible explanation for this is that patients are usually more satisfied at highquality hospitals that provide better care, including better surgical care ${ }^{2}$. However, a previous study concluded that the physical environment has a minor impact on satisfaction, suggesting that "nontechnical" details are what really matters, and satisfaction is about interacting well with patients ${ }^{5}$. Despite the presence of solid evidence to support the positive impact of patient satisfaction on outcomes in general, data on surgical outcomes is still inconclusive. Surgical outcomes have also been suggested to be positively affected by improved patient satisfaction, although this is still unclear, and contrasting results of this association have been reported ${ }^{2,6}$. This makes further studies on the relation between patient satisfaction and surgical care essential to either confirm or deny it.

Hospitals in developed countries have been using the Hospital Consumer Assessment of Healthcare Providers and Systems (HCAHPS) survey to assess satisfaction of hospitalized patients and guarantee continuous quality improvement. ${ }^{4,6}$ HCAHPS is the first survey that accurately measures patient satisfaction and provides data that could be compared between hospitals. It was originally developed by the Centers for Medicare and Medicaid Services (CMS) and the Agency for Healthcare Research and Quality, and it was approved for use in 2005. Since then, it has been continuously in development ${ }^{3,7}$. On the other hand, hospitals in developing countries in general, and the Middle East specifically, still lack accurate data on patient satisfaction. Egypt, one of the largest countries in the region, has not focused on evaluating patient satisfaction with health care service.

Injuries and trauma continue to be a major concern and are the most common causes of morbidity and mortality in Egypt $^{8,9}$. In this study, we used the official Arabic translation of the HCAHPS survey to measure the level of patient satisfaction in admitted trauma patients at Ain Shams University Surgery Hospital in Egypt.

\section{Methodology}

We conducted a cross-sectional study using an HCAHPSderived survey.

\section{Data Source}

We collected data on patients who were treated at Ain Shams University Surgery Hospital between November 2015 and July 2018.

\section{Study Population}

The study included 1,473 trauma patients older than 18 years who had been admitted to Ain Shams University Surgery Hospital for at least two days and were then discharged. Most of our patients were admitted to the orthopedics department (Table 1).We included variable demographic population in our study based on the gender, Education, Residence and previous admissions, The majority of our study population was males residing outside Cairo with no previous admission to El-Demerdash hospital (Table 2) We excluded patients diagnosed with a psychiatric illness, patients with a foreign

Table I A Multiple Ordinal Regression Model Describing the Predictors of Hospital Ratings

\begin{tabular}{|c|c|c|c|c|}
\hline \multirow[t]{2}{*}{ Predictors } & \multirow[t]{2}{*}{ OR } & \multirow[t]{2}{*}{ Sig. } & \multicolumn{2}{|c|}{ 95\% Confidence Interval } \\
\hline & & & Lower Bound & Upper Bound \\
\hline Orthopedics department & 0.55 & 0.015 & 0.35 & 0.89 \\
\hline Another department ${ }^{a}$ & I & & & \\
\hline Delayed examination in ER & 0.12 & $<0.001$ & 0.07 & 0.19 \\
\hline No delay ${ }^{a}$ & 1 & & & \\
\hline Surgery done & 2.08 & 0.003 & 1.29 & 3.34 \\
\hline No surgery ${ }^{a}$ & I & & & \\
\hline Previous hospitalization & 0.69 & 0.117 & 0.43 & 1.10 \\
\hline No previous hospitalization ${ }^{\text {a }}$ & I & & & \\
\hline Condition improved & 1.79 & 0.153 & 0.81 & 3.96 \\
\hline Condition not improved ${ }^{a}$ & I & & & \\
\hline General condition: good & 1.14 & 0.575 & 0.72 & 1.81 \\
\hline General condition: not good ${ }^{a}$ & I & & & \\
\hline
\end{tabular}

Notes: A multiple ordinal regression was used. Predicted: Hospital rating "below 5," below "5-7," and below "8-10" Model significance < $0.00 \mathrm{I}$, Pseudo R-squared = $0.3 \mathrm{I} 3$.

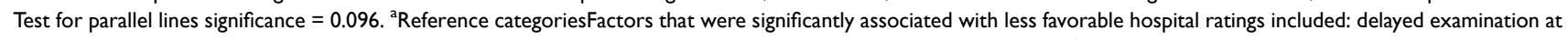
the emergency room and admission to the orthopedics department. Having had surgery was associated with a significantly better hospital rating. 
Table 2 Demographic Characteristics and Medical History of the Participants

\begin{tabular}{|l|l|c|c|}
\hline & & Number & Percentage \\
\hline Gender & Male & 278 & $77.0 \%$ \\
& Female & 83 & $23.0 \%$ \\
\hline Education & No education & 64 & $17.7 \%$ \\
& Primary & 43 & $11.9 \%$ \\
& Secondary & 84 & $23.3 \%$ \\
& High school & 130 & $36.0 \%$ \\
& University & 40 & $11.1 \%$ \\
\hline Residence & Cairo & 119 & $33.0 \%$ \\
& Other & 242 & $67.0 \%$ \\
\hline Previous admission & No & 252 & $69.80 \%$ \\
& El Demerdash & 16 & $4.40 \%$ \\
& Other ASU & 10 & $2.80 \%$ \\
& hospital & & \\
& Other & 83 & $23.00 \%$ \\
& hospital & & \\
\hline Self-reported General & Bad & 30 & $8.30 \%$ \\
& Accepted & 86 & $23.80 \%$ \\
condition & Good & 93 & $25.80 \%$ \\
& Very good & 110 & $30.50 \%$ \\
& Excellent & 42 & $11.60 \%$ \\
\hline & Total & 361 & $100 \%$ \\
\hline
\end{tabular}

Notes: The data showed that most of our patients were males, lived outside of Cairo, and had no previous hospital admission.

home address, patients discharged to hospice care (hospicehome or hospice-medical facility), patients discharged to nursing homes and skilled nursing facilities, patients who refused to be contacted following discharge, and patients who did not consent to participate in the study. We obtained verbal consent from all participating patients because many of our patients did not get enough education (Table 2) The sample was collected conveniently within a duration of 12 months.
After the patients were discharged from the hospital, the study patients were contacted by phone to arrange a meeting with them. The four approved modes of administration for the CAHPS ${ }^{\circledR}$ Hospital Survey were: 1) mail only; 2) telephone only; 3) mixed (mail followed by telephone); and 4) active interactive voice response (IVR). ${ }^{7}$ Due to the inapplicability of the mail and IVR in Egypt, we used "interviewer facilitated survey" or "telephone only" modes according to the availability of the patient. Patients were interviewed by an independent investigator who explained the aim of the survey. For patients who were not able to arrange a meeting within the first three weeks following discharge, an independent investigator carried out the interview on the phone. All investigators were trained medical students.

The following demographic variables were recorded for each study participant: age, sex, education, and residence. The HCAHPS survey included 32 questions and listed 21 patient perspectives on care and patient rating items that encompassed nine key topics: communication with doctors, communication with nurses, responsiveness of hospital staff, pain management, communication about medicines, discharge information, cleanliness of the hospital environment, quietness of the hospital environment, and transition of care. The survey also included four screening questions and seven demographic items, which were used for adjusting the mix of patients throughout the hospital and for analytical purposes ${ }^{7}$.

\section{Outcomes}

We assessed the level of patient satisfaction using HCAHPS measures and calculated the mean score for patient satisfaction for the included patients along with the mean score for different predictors of patient satisfaction in relation to the main variables (perceived waiting time, prior hospitalization, and perceived health status on discharge compared to admission). We established the

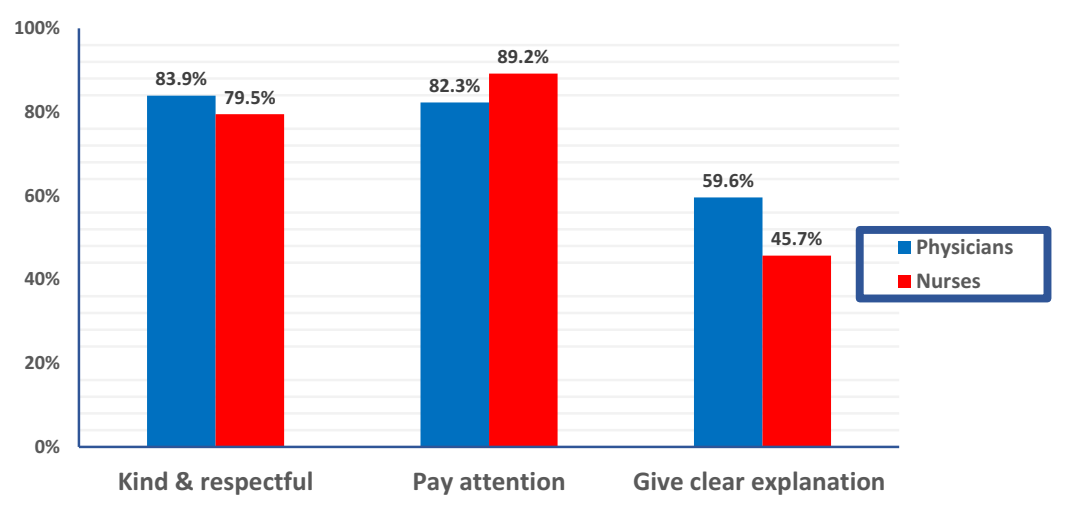

Figure I Evaluation of medical staff (physicians and nurses). The graph shows the percentage of patients who answered, "most of the time" or "always." More than half of the participants $(60.7 \%)$ stated that the nursing staff provided immediate assistance when asked most of the time or always. 
baseline level of patient satisfaction using the HCAHPSderived survey for admitted trauma patients in Ain Shams University Surgery Hospital. The differences in patient satisfaction scores were determined for trauma patients with respect to known predictor variables such as age, sex, educational level, and perceived waiting time.

\section{Statistical Analysis}

Statistical analysis was performed with SPSS version 23. Qualitative variables were presented in the form of frequency and percentage. Bar charts were used to demonstrate the percentages graphically. Quantitative data were presented as the mean and standard deviation. Means were compared using an independent sample $t$-test and a oneway ANOVA test. A multiple ordinal regression model was used to describe the predictors associated with patient ratings of El-Demerdash Hospital. For all tests, $\mathrm{P}$ values $\leq 0.05$ were considered statistically significant.

\section{Results}

A total of 1,473 patients were included in the study. Three hundred and sixty-one participants were interviewed, 101 (28\%) through face-to-face interviews and the remaining $260(72 \%)$ through telephone calls. Those who could not

Table 3 Univariate Analysis Comparing the Mean Hospital Rating According to Demographic and Hospitalization Characteristics

\begin{tabular}{|c|c|c|c|c|c|}
\hline \multicolumn{2}{|l|}{ Characteristic } & \multirow{3}{*}{$\begin{array}{l}\mathbf{N} \\
242 \\
119\end{array}$} & \multicolumn{2}{|c|}{ Hospital Rating } & \multirow{3}{*}{$\begin{array}{l}\text { P value } \\
0.266^{\mathrm{a}}\end{array}$} \\
\hline & & & \multirow{2}{*}{$\begin{array}{c}\text { Mean } \\
6.88 \\
7.17\end{array}$} & \multirow{2}{*}{$\begin{array}{l}\text { SE } \\
0.18 \\
0.19\end{array}$} & \\
\hline Age & $\begin{array}{l}<40 \\
\geq 40\end{array}$ & & & & \\
\hline Gender & $\begin{array}{l}\text { Male } \\
\text { Female }\end{array}$ & $\begin{array}{c}278 \\
83\end{array}$ & $\begin{array}{l}6.95 \\
7.06\end{array}$ & $\begin{array}{l}0.15 \\
0.27\end{array}$ & $0.728^{b}$ \\
\hline Education & $\begin{array}{l}\text { No education } \\
\text { Some education } \\
\text { Secondary/ high education }\end{array}$ & $\begin{array}{c}64 \\
127 \\
170\end{array}$ & $\begin{array}{l}7.38 \\
7.14 \\
6.70\end{array}$ & $\begin{array}{l}0.39 \\
0.19 \\
0.20\end{array}$ & $0.127^{c}$ \\
\hline Residence & $\begin{array}{l}\text { Cairo } \\
\text { Other }\end{array}$ & $\begin{array}{l}119 \\
242\end{array}$ & $\begin{array}{l}6.91 \\
7.01\end{array}$ & $\begin{array}{l}0.23 \\
0.17\end{array}$ & $0.724^{b}$ \\
\hline Admission day & $\begin{array}{l}\text { Weekday } \\
\text { Weekend/ Holiday }\end{array}$ & $\begin{array}{c}283 \\
78\end{array}$ & $\begin{array}{l}7.01 \\
6.83\end{array}$ & $\begin{array}{l}0.14 \\
0.35\end{array}$ & $0.633^{\mathrm{a}}$ \\
\hline Admission time & $\begin{array}{l}\text { Day shift } \\
\text { Night shift }\end{array}$ & $\begin{array}{l}241 \\
120\end{array}$ & $\begin{array}{l}6.80 \\
7.32\end{array}$ & $\begin{array}{l}0.17 \\
0.21\end{array}$ & $0.07 I^{b}$ \\
\hline Department & $\begin{array}{l}\text { Orthopedics } \\
\text { Other }\end{array}$ & $\begin{array}{l}237 \\
124\end{array}$ & $\begin{array}{l}6.85 \\
7.21\end{array}$ & $\begin{array}{l}0.16 \\
0.24\end{array}$ & $0.205^{\mathrm{b}}$ \\
\hline Delayed examination at ER & $\begin{array}{l}\text { No delay } \\
\text { Some delay }\end{array}$ & $\begin{array}{l}217 \\
144\end{array}$ & $\begin{array}{l}7.95 \\
5.51\end{array}$ & $\begin{array}{l}0.12 \\
0.24\end{array}$ & $<0.001^{a}$ \\
\hline Surgery & $\begin{array}{l}\text { No } \\
\text { Yes }\end{array}$ & $\begin{array}{l}103 \\
258\end{array}$ & $\begin{array}{l}6.09 \\
7.33\end{array}$ & $\begin{array}{l}0.29 \\
0.14\end{array}$ & $<0.001^{\mathrm{a}}$ \\
\hline ICU admission & $\begin{array}{l}\text { No } \\
\text { Yes }\end{array}$ & $\begin{array}{c}337 \\
24\end{array}$ & $\begin{array}{l}7.02 \\
6.33\end{array}$ & $\begin{array}{l}0.14 \\
0.61\end{array}$ & $0.280^{\mathrm{b}}$ \\
\hline Current condition & $\begin{array}{l}\text { Not improved } \\
\text { Improved }\end{array}$ & $\begin{array}{c}29 \\
332\end{array}$ & $\begin{array}{l}5.93 \\
7.07\end{array}$ & $\begin{array}{l}0.61 \\
0.13\end{array}$ & $0.081^{\mathrm{a}}$ \\
\hline Previous admission & $\begin{array}{l}\text { No } \\
\text { Yes }\end{array}$ & $\begin{array}{l}252 \\
109\end{array}$ & $\begin{array}{l}7.17 \\
6.51\end{array}$ & $\begin{array}{l}0.16 \\
0.25\end{array}$ & $0.020^{\mathrm{a}}$ \\
\hline General condition & $\begin{array}{l}\text { Bad/ accepted } \\
\text { Good }\end{array}$ & $\begin{array}{l}116 \\
245\end{array}$ & $\begin{array}{l}6.41 \\
7.24\end{array}$ & $\begin{array}{l}0.27 \\
0.15\end{array}$ & $0.007^{\mathrm{a}}$ \\
\hline
\end{tabular}

Notes: ${ }^{a} A n$ independent samples $t$-test was used. Equal variances were not assumed. ${ }^{\mathrm{b}} \mathrm{An}$ independent samples $t$-test was used. Equal variances were assumed. ${ }^{\mathrm{C}} \mathrm{A}$ one-way ANOVA test was used.

Abbreviations: SE, Standard Error of the Mean. 
be interviewed did not meet our inclusion criteria [children (266), stayed less than two days (83), dead (18), and psychiatric illness (9) or fit the inclusion criteria but we could not contact them (no phone number/no replies, refused to be interviewed, and no follow up). The age of the participants ranged between 19 and 70 years with a median of 35 years (interquartile range: 27-44).

\section{Discussion}

The goal of the healthcare system is to provide the best possible care to patients. The HCAHPS survey was designed to measure the quality of this care and follow up on improvements to the healthcare system to deliver the highest possible outcomes while monitoring patient satisfaction over time. ${ }^{10}$ However, it is still unclear whether there is an association between HCAHPS scores and healthcare quality ${ }^{11,12}$.

We initially enrolled 699 patients who met our inclusion criteria, but we could not reach out to some of them for different reasons. This means if we could not reach out to them the hospital could not reach out to them as well, which is unsettling. Therefore, the hospital needs to keep better track of their patients and maintain electronic copies of valid contacts for their patients. The hospital uses paper records for the patients, which can be easily misplaced or lost. We therefore recommend replacing the paper system with an electronic system.

As our results showed, there was diversity and variety in the demographic representations of our patients and $67 \%$ of the patients resided outside of Cairo (Table 2 and 3 ). This can be explained by the Ain
Shams University Surgery Hospital being one of the largest government hospitals in Cairo. It serves many patients on a daily basis from all over Egypt. Also, most of our patients were males (Table 3) and this can be explained by the fact that males are involved in accidents more often. The results showed some positives and negatives about the hospital. The positives included no delay in the emergency room before admission. This could be due to Egyptian patients and families being aggressive and they usually do not like to wait. This is why many violent episodes and fights have been recorded in Ain Shams University Surgery Hospital. Another positive finding was that most of the patients mentioned that the medical staff, including nurses and doctors, were friendly, helpful, and caring.

The results also showed some negative attitudes regarding improper communication between the medical staff and patients. $82.3 \%$ of the patients indicated their own preferences were not taken into consideration. Moreover, they felt they had not received clear explanations in the discharge notes, and the indications of the new medications and side effects were unclear (Figure 2). We suggest the explanation for improper communication between the medical staff and patients is that the medical students at Ain shams University do not study communication skills and there are no regular communication skills courses offered to the medical staff in the hospital. Moreover, the workload on the physicians is greater than usual in Ain Shams University Surgery Hospital.

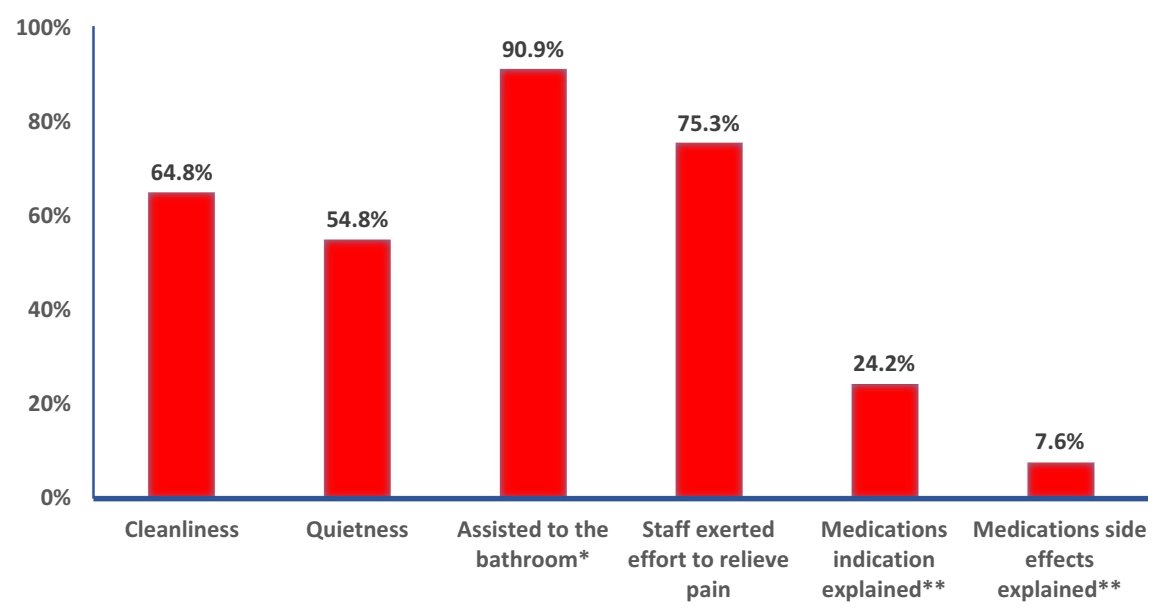

Figure 2 Evaluation of the hospital environment. The graph shows the percentage of patients who answered, "most of the time" or "always." Two hundred and forty-eight patients received medications they had not heard about previously. Only $24.2 \%$ of them stated they had received an explanation about the indications for the medicine. Only $7.6 \%$ were told about the side effects of the medications they were given. A total of 325 patients stated they needed analgesics; $81.2 \%$ of them stated they responded to analgesics. 
Surprisingly, the patients' overall rating for the hospital was very positive (Table 4). $60 \%$ of our patients reported no delay in the Admission from the Emergency room and $90 \%$ of the patients felt they had better condition after leaving the hospital (Table 5). Moreover $90.9 \%$ of the patients were assisted to go to the bathroom, $75.3 \%$ of the patients felt that the staff exerted some effort to relieve their pain (Figure 2) while $64.8 \%$ of the population found their rooms and bathrooms clean (Figure 1) They were mostly satisfied as $48.8 \%$ of the patients rated the overall experience with a score over 8 on a score level from (1-10) and $79.2 \%$ of the patients would recommend the hospital to friends and relatives (Figure 3).

Table 4 Overall Satisfaction Regarding the Last Admission to El-Demerdash Hospital

\begin{tabular}{|l|l|c|c|}
\hline & & Number & Percentage \\
\hline Rating hospital "On a scale of I-10" & $<5$ & 44 & $12.2 \%$ \\
& $5-7$ & 141 & $39.1 \%$ \\
& $8-10$ & 176 & $48.8 \%$ \\
\hline Recommend EL-Demerdash hospital to family/friends & Of course, Not & 57 & $15.8 \%$ \\
& Mostly No & 18 & $5.0 \%$ \\
& Mostly Yes & 121 & $33.5 \%$ \\
& Of course, Yes & 165 & $45.7 \%$ \\
\hline & Total & 361 & $100 \%$ \\
\hline
\end{tabular}

Table 5 Data on the Last Admission to Ain Shams University Surgery Hospital

\begin{tabular}{|c|c|c|c|}
\hline & & Number & Percentage \\
\hline \multirow[t]{4}{*}{ Department } & Surgery & 34 & $9.4 \%$ \\
\hline & Orthopedics & 237 & $65.7 \%$ \\
\hline & Plastic surgery & 86 & $23.8 \%$ \\
\hline & Neurosurgery & 4 & $1.1 \%$ \\
\hline \multirow[t]{3}{*}{ Admission day } & Weekday & 283 & $78.4 \%$ \\
\hline & Weekend & 37 & $10.2 \%$ \\
\hline & Holiday & 41 & $11.4 \%$ \\
\hline \multirow[t]{2}{*}{ Admission time } & Day shift 8 am-8 pm & 241 & $66.8 \%$ \\
\hline & Night shift 8 pm-8 am & 120 & $33.2 \%$ \\
\hline \multirow[t]{4}{*}{ Delayed examination at emergency room (ER) } & No delay & 217 & $60.10 \%$ \\
\hline & A little delay & 63 & $17.50 \%$ \\
\hline & Very delayed & 69 & $19.10 \%$ \\
\hline & Do not know & 12 & $3.30 \%$ \\
\hline \multirow[t]{2}{*}{ Surgery } & No & 103 & $28.5 \%$ \\
\hline & Yes & 258 & $71.5 \%$ \\
\hline \multirow[t]{2}{*}{ ICU admission } & No & 337 & $93.4 \%$ \\
\hline & Yes & 24 & $6.6 \%$ \\
\hline \multirow[t]{3}{*}{ Destination after discharge } & Home & 341 & $94.5 \%$ \\
\hline & Other health care facility & 15 & $4.2 \%$ \\
\hline & Another house & 5 & $1.4 \%$ \\
\hline \multirow[t]{5}{*}{ Current condition compared to time at admission } & Worse & 14 & $3.90 \%$ \\
\hline & No change & 15 & $4.20 \%$ \\
\hline & A little better & 186 & $51.50 \%$ \\
\hline & Much better & 146 & $40.40 \%$ \\
\hline & Total & 361 & $100 \%$ \\
\hline
\end{tabular}

Notes: Most of the patients were admitted to the Orthopedics Department with no delay in the admission time and they went home after surgery. 


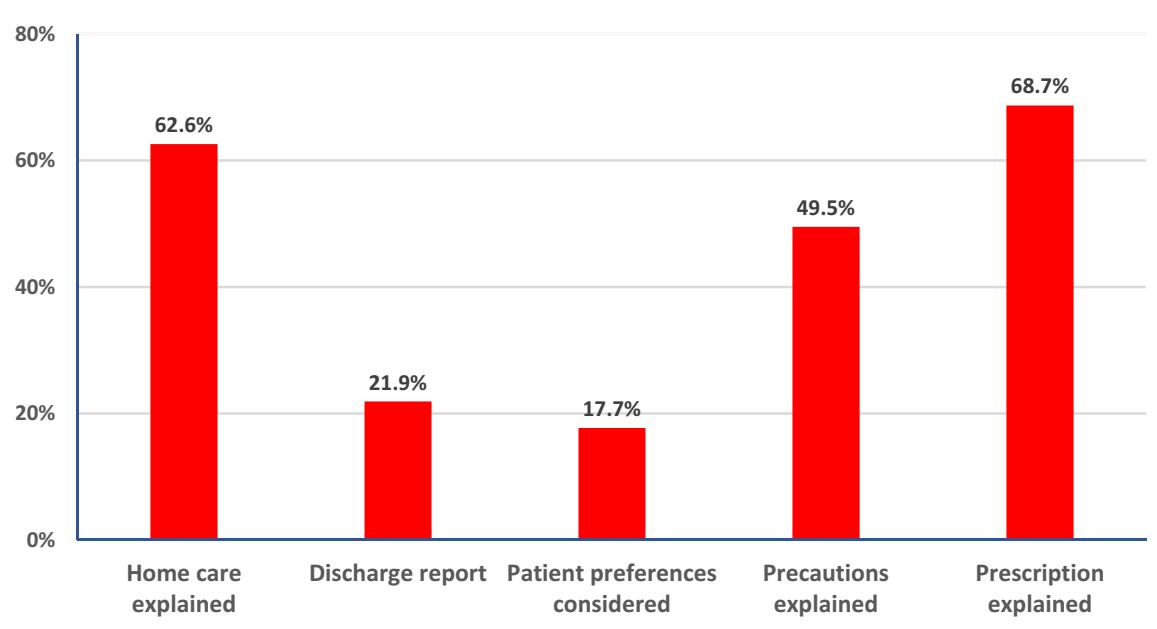

Figure 3 Medical care at the time of discharge. The graph shows the percentage of patients who answered, "most of the time" or "always."

Despite the negative answers, the results showed that Egyptian patients are kind and can forgive mistakes as long as they are treated properly, and their pain is relieved $(91.9 \%$ of patients felt better than at the time of admission). Also, patients with previous governmental hospital experience found Ain Shams University Surgery Hospital to be much better than the other governmental hospitals, which made them more satisfied with the services they received. The patients went home directly after surgery without going to a skilled nursing facility. This implies a need for skilled nursing facilities in Egypt, which could increase patient satisfaction and improve outcomes.

The results showed that nurses do not give clear explanations mostly due to a lack of communication skills. This may be due to nursing schools not offering communication skills courses, which should be organized by the hospital from time to time. The cleanliness and quietness of the hospital were not optimal for the patients and these needs to be improved.

\section{Conclusion}

Patient satisfaction is mainly achieved by a patientcentered approach that focuses on a proper understanding and involvement of the patient in the provided care. Studies have suggested that higher patient satisfaction can be associated with significantly better outcomes. ${ }^{2}$ This study was the first carried out at Ain Shams University Surgery Hospital that pointed out the positives and the negatives of the hospital systems. The medical staff at Ain Shams University Surgery Hospital should focus more on the patient's own preferences and communicate better with the patients. We recommended that Ain Shams University Surgery Hospital organize regular communication skills courses for medical students, physicians, and nurses. Patients should understand the discharge report well, and the indications and side effects of medications should be made clear before leaving the hospital.

\section{Recommendations}

1. -Organizing communication skills courses for medical students at Ain Shams University.

2. -Organizing regular communication skills courses for doctors and nurses at EL-Demerdash hospital.

3. -Maintain a proper record system for the patients by replacing paper records with an electronic system.

4. -Developing skilled nursing facilities as a transitional place between the hospital and patients' homes could increase patient satisfaction and decrease the duration of stays at the hospital.

5. -Carry out follow up evaluation for El-DEmerdash patient satisfaction over the next five years.

\section{Ethics Approval}

In This Retrospective study, verbal consent was approved by the institutional review boards. This study was conducted in accordance with the declaration of Helsinki. We waived the written consent because the illiteracy rate in Egypt is about $30 \%$, especially the residents of the rural areas around Cairo who Can't even sign their names. We had verbal consents from the patients after explaining everything about the study then they had sufficient time to refuse or accept. We made sure to interview them after they had received their medical care completely to comfort them that their opinions wouldn't affect their medical care. 
The Institutional Review Board (IRB) of Ain Shams University, Cairo, Egypt approved the study. Date: January 2015, Reference: IRB 00006379

The Institutional Review Board (IRB) of the University of Maryland, Baltimore, USA approved the study. Date: March 2015, Reference: HP-00062968

\section{Funding}

This work was funded by the National Institutes of Health, Fogarty International Center, USA through grant number 2D43TW007296.

\section{Disclosure}

Jon Mark Hirshon reports grants from NIH Fogarty International Center, during the conduct of the study. The authors report no other potential conflicts of interest for this work.

\section{References}

1. Donabedian A. The quality of care. How can it be assessed? JAMA. 1988;260(12):1743-1748.doi:10.1001/jama.1988.03410120089033.

2. Tsai TC, Orav EJ, Jha AK. Patient satisfaction and quality of surgical care in us hospitals thomas. Ann Surg. 2016;261(1):2-8.

3. Tevis SE, Kennedy GD, Kent KC. Is there a relationship between job satisfaction and absenteeism? J Adv Nurs. 1996;23(1):827-834.
4. Glickman SW, Boulding W, Manary M, et al. Patient satisfaction and its relationship with clinical quality and inpatient mortality in acute myocardial infarction. Circ Cardiovasc Qual Outcomes. 2010;3 (2):188-195.

5. Boulding W, Glickman SW, Manary MP, Schulman KA, Staelin R. Relationship between patient satisfaction with inpatient care and hospital readmission within 30 days. Am J Manag Care. 2011;17 (1):41-48.

6. Sacks GD, Lawson EH, Dawes AJ, et al. Relationship between hospital performance on a patient satisfaction survey and surgical quality. JAMA Surg. 2015;150(9):858-864.

7. Centers for Medicare \& Medicaid Services. HCAHPS_Fact_Sheet_November_2017; 2017:1-5. Available from: http://www.hcahpsonline.org/Files/HCAHPS_Fact_Sheet_ November_2017a.pdf. Accessed September 16, 2021.

8. Mahran DG, Farouk O, Qayed MH, Berraud A. Pattern and trend of injuries among trauma unit attendants in upper Egypt. Trauma Mon. 2016;21(2):e20967.

9. Mahran D, Farouk O, Qayed M, Berraud A. Hospitalized injuries and deaths in a trauma unit in upper Egypt. Int J Crit Illn Inj Sci. 2013;3 (4):235.

10. Mann RK, Siddiqui Z, Kurbanova N, Qayyum R. Effect of HCAHPS reporting on patient satisfaction with physician communication. J Hosp Med. 2016;11(2):105-110. doi:10.1002/jhm.2490

11. Isaac T, Zaslavsky AM, Cleary PD, Landon BE. The relationship between patients ' perception of care and measures of hospital quality and safety. Health Serv Res. 2010;45(4):1024-1040. doi:10.1111/ j.1475-6773.2010.01122.x

12. Malpani R, Hilibrand AS, Grauer JN. Evolution and use of hospital consumer assessment of healthcare providers and systems (HCAHPS) surveys and their application for spinal surgery patients. Contemp Spine Surg. 2018;19(5):1-6.
Journal of Multidisciplinary Healthcare

\section{Publish your work in this journal}

The Journal of Multidisciplinary Healthcare is an international, peerreviewed open-access journal that aims to represent and publish research in healthcare areas delivered by practitioners of different disciplines. This includes studies and reviews conducted by multidisciplinary teams as well as research which evaluates the results or conduct of such teams or healthcare processes in general. The journal

\section{Dovepress}

covers a very wide range of areas and welcomes submissions from practitioners at all levels, from all over the world. The manuscript management system is completely online and includes a very quick and fair peer-review system. Visit http://www.dovepress.com/testimonials. php to read real quotes from published authors. 